\title{
Crystallization and Preliminary Crystallographic Studies of Dimethyl Sulfoxide Reductase from Rhodobacter sphaeroides f. sp. denitrificans
}

\author{
By Kiichi Sato, ${ }^{*)}$ Hiroshi SaSaki, ${ }^{* *)}$ Akira OKubo, ${ }^{*)}$ Masaru Tanokura, ${ }^{* *), * * *)}$ \\ and Sunao YAMAZAKI*)
}

(Communicated by Setsuro EBASHI, M. J. A., Feb. 12, 1997)

\begin{abstract}
DMSO reductase from Rhodobacter sphaeroides f. sp. denitrificans was crystallized by the hanging-drop vapor diffusion method, using ammonium sulfate as a precipitant. The space group of the crystal was $P 2_{1} 2{ }_{1} 2$, with unit-cell dimensions of $a=76.1 \AA, b=203.4 \AA$, and $c=62.2 \AA$. Assuming one protein molecule per asymmetric unit, the solvent content was estimated to be $56 \%$.
\end{abstract}

Key words : Crystallization; dimethyl sulfoxide reductase; Rhodobacter sphaeroides $\mathrm{f}$. sp. denitrificans; X-ray crystallography.

Introduction. A wide variety of organisms are known to reduce dimethyl sulfoxide (DMSO) to dimethyl sulfide, ${ }^{1)}$ and some bacteria are able to grow by DMSO respiration under anaerobic conditions. ${ }^{2)}$ The terminal enzyme of the DMSO respiration, DMSO reductase, has been purified from several bacteria. Rhodobacter sphaeroides f. sp. denitrificans ${ }^{3)}$ is a facultative photosynthetic bacterium, which can grow depending on dimethyl sulfoxide respiration as an energy-generating system other than $\mathrm{O}_{2}$ respiration, denitrification and photosynthesis. DMSO reductase from $R$. sphaeroides f. sp. denitrificans was isolated as a monomer (molecular mass $85 \mathrm{kDa}$ ) and contains a molybdopterin cofactor as a sole prosthetic group. ${ }^{4)}$ The cofactor was the first one reported in bacteria that contains guanine dinucleotide ${ }^{5)}$ and consisted of two pterin molecules per one molybdenum. ${ }^{6}$ The enzyme can reduce a wide variety of sulfoxides and $N$-oxides including methionine sulfoxide, biotin sulfoxide and alkyl aryl sulfoxides. ${ }^{4), 7), 8)}$

Although the primary structure of the protein was obtained by DNA sequence analysis, ${ }^{9)}$ the detailed

*) Department of Applied Biological Chemistry, The University of Tokyo, 1-1-1 Yayoi, Bunkyo-ku, Tokyo 113, Japan.

**) Biotechnology Research Center, The University of Tokyo, 1-1-1 Yayoi, Bunkyo-ku, Tokyo 113, Japan.

***) Center for Tsukuba Advanced Research Alliance (TARA guest researcher for Sakabe project), University of Tsukuba, Tsukuba, Ibaraki 305, Japan. three-dimensional structure of the enzyme and the function of the molybdopterin cofactor had been still in the vague. Very recently, the crystal structure of the enzyme was reported, ${ }^{10}$ ) in which the atomic coordinates of 768 out of 780 amino acids were well defined. However, those of remaining 12 amino acids from $\mathrm{Lys}^{381}$ to $\mathrm{Gly}^{393}$ were not fixed presumably due to the mobility of this part in the crystal. It was reported that this region was quite susceptible to protease digestion and that introduction of only one nick in this region by partial digestion with trypsin or Staphylococcus aureus protease resulted in a two- to three-fold enhancement of the specific activity. ${ }^{11)}$ More detailed structure analysis is of the utmost importance to understand the role of this peptide region on the enzyme activity. In this paper, we report preliminary crystallographic studies using crystals of $R$. sphaeroides DMSO reductase which were different in crystal form from that reported.

Materials and methods. For crystallization, DMSO reductase from $R$. sphaeroides f. sp. denitrificans was purified to homogeneity as below. Culture conditions, preparation of the periplasmic fraction and ammonium sulfate fractionation were performed as reported by Satoh and Kurihara. ${ }^{4)}$ Proteins precipitated with ammonium sulfate were dissolved in $50 \mathrm{mM}$ Tris- $\mathrm{HCl}$ buffer ( $\mathrm{pH}$ 7.5) and dialyzed overnight against the same buffer. The dialyzed fraction was clarified by centrifugation and loaded onto a DEAE Sepharose FF column (Pharmacia) equilibrated with 


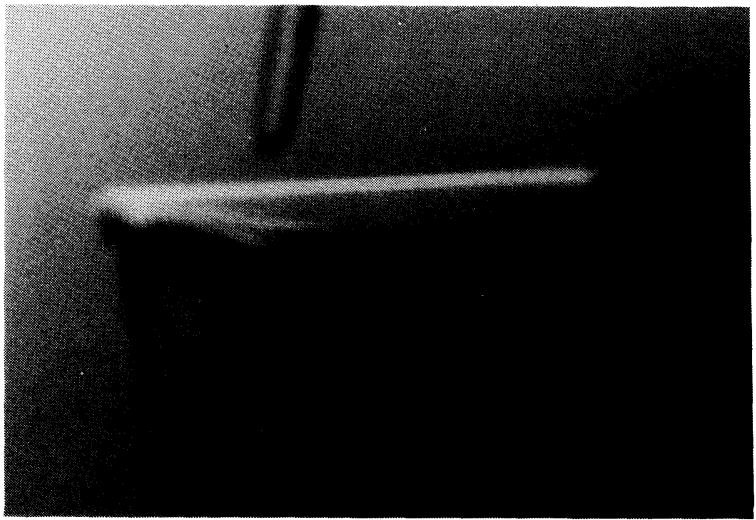

Fig. 1. A single crystal of dimethyl sulfoxide reductase.

$50 \mathrm{mM}$ Tris- $\mathrm{HCl}$ buffer $(\mathrm{pH}$ 7.5) and eluted with $0.15-0.4 \mathrm{M} \mathrm{NaCl}$ gradient in $50 \mathrm{mM}$ Tris- $\mathrm{HCl}$ buffer (pH 7.5). DMSO reductase containing fractions were pooled and concentrated with a YM30 membrane filter (Amicon), and loaded onto a Superdex 200 p.g. column (Pharmacia) equilibrated with $0.25 \mathrm{M} \mathrm{NaCl}$ in $50 \mathrm{mM}$ Tris-HCl buffer ( $\mathrm{pH}$ 7.5). The enzyme was eluted with the same buffer, and the fractions containing DMSO reductase activity were combined. This solution was concentrated by ultrafiltration and diluted with $50 \mathrm{mM}$ Tris-HCl buffer ( $\mathrm{pH}$ 7.5), and then loaded onto a Mono $\mathrm{Q}$ column (Pharmacia) equilibrated with $50 \mathrm{mM}$ Tris$\mathrm{HCl}$ buffer (pH 7.5) and eluted with $0.15-0.4 \mathrm{M} \mathrm{NaCl}$ gradient in $50 \mathrm{mM}$ Tris- $\mathrm{HCl}$ buffer $(\mathrm{pH}$ 7.5). The fractions with maximal specific activity were pooled and concentrated by ultrafiltration. DMSO reductase activity was measured with dithionite reduced benzyl viologen cation radical as reported previously. ${ }^{4)}$ The protein concentration was estimated by the bicinchoninic acid method ${ }^{12)}$ using reagents from Pierce with BSA as a standard.

The hanging-drop vapor diffusion method was employed at 10 and $20^{\circ} \mathrm{C}$ to survey the optimal crystallization conditions using the sparse-matrix method $^{13)}$ for initial screening. Further search of crystallization conditions was performed with ammonium sulfate, over the $\mathrm{pH}$ range of 6.0 to 9.0 and at DMSO concentrations between $0 \%$ and $8 \%$.

Preliminary X-ray diffraction experiments and the collection of the intensity data were performed with a data collection system at the BL6B Station in the Photon Factory of the National Laboratory for High Energy Physics, by combining the Weissenberg camera for macromolecular crystallography, an imaging plate, a large image reader (IPR4080), and programs, WEIS, ROTAVATA and AGROVATA,
Table I. Crystallographic parameters of dimethyl sulfoxide reductase

\begin{tabular}{cc}
\hline Crystal system & Orthorhombic \\
Space group & $P 2_{1} 2_{1} 2$ \\
Cell dimensions & $a=76.1 \AA$ \\
& $b=203.4 \AA$ \\
$V_{\text {sol }}$ & $c=62.2 \AA$ \\
Resolution & $56 \%$ \\
$R_{\text {merge }}$ & $2.7 \AA$ \\
\hline
\end{tabular}

Table II. Statistics of the collected X-ray diffraction intensity data of dimethyl sulfoxide reductase

\begin{tabular}{rrrc}
\hline Resolution $(\AA)$ & Completion (\%) & I/Sigma I & Merging R-Factor \\
\hline-11.99 & 98.9 & 10.7 & 0.045 \\
$11.99-8.51$ & 100.0 & 12.7 & 0.046 \\
$8.51-6.96$ & 98.4 & 11.0 & 0.054 \\
$6.96-6.03$ & 100.0 & 10.6 & 0.059 \\
$6.03-5.39$ & 97.0 & 9.2 & 0.065 \\
$5.39-4.93$ & 94.2 & 9.5 & 0.063 \\
$4.93-4.56$ & 90.3 & 9.9 & 0.061 \\
$4.56-4.27$ & 86.4 & 9.5 & 0.063 \\
$4.27-4.02$ & 85.0 & 9.3 & 0.069 \\
$4.02-3.82$ & 83.8 & 8.0 & 0.077 \\
$3.82-3.64$ & 81.6 & 8.4 & 0.079 \\
$3.64-3.48$ & 80.1 & 7.6 & 0.089 \\
$3.48-3.35$ & 78.7 & 7.2 & 0.095 \\
$3.35-3.23$ & 76.0 & 6.3 & 0.110 \\
$3.23-3.12$ & 74.4 & 5.2 & 0.135 \\
$3.12-3.02$ & 73.0 & 4.8 & 0.147 \\
$3.02-2.93$ & 70.3 & 4.3 & 0.162 \\
$2.93-2.85$ & 67.4 & 3.9 & 0.186 \\
$2.85-2.77$ & 64.4 & 3.5 & 0.209 \\
$2.77-2.70$ & 61.3 & 3.3 & 0.219 \\
\hline
\end{tabular}

with synchrotron radiation. ${ }^{14)-18)}$

Results and discussion. The crystals used for preliminary crystallographic studies were prepared at $20^{\circ} \mathrm{C}$ in a mixture of equal volumes $(7 \mu \mathrm{l}$ each) of a protein solution (30 $\mathrm{mg}$ protein $/ \mathrm{ml}$ in $10 \mathrm{mM}$ Tris- $\mathrm{HCl}$ buffer, $\mathrm{pH}$ 7.5) and a reservoir buffer $(1.85 \mathrm{M}$ ammonium sulfate and $0.1 \mathrm{M}$ Tris- $\mathrm{HCl}$ buffer, $\mathrm{pH}$ 8.25). Crystals appeared after a few days and continued to grow as thin needles up to a maximum size of $0.03 \mathrm{~mm} \times 0.1 \mathrm{~mm} \times 1.5 \mathrm{~mm}$ (Fig. 1).

The crystals were determined to belong to orthorhombic space group $P 2_{1} 2_{1} 2$, and the unit cell dimensions were $a=76.1 \AA, b=203.4 \AA$, and $c=62.2 \AA$ (Table I). On the assumption of one enzyme molecule per asymmetric unit, the volume to unit protein mass ratio $\left(V_{\mathrm{m}}\right)$ was calculated to be $2.8 \AA^{3} / \mathrm{Da}$. By assuming the specific volume of the crystals to be $0.74 \mathrm{~cm}^{3} / \mathrm{g},{ }^{19}$ ) the solvent content $\left(V_{\text {sol }}\right)$ was estimated to be $56 \%$. 


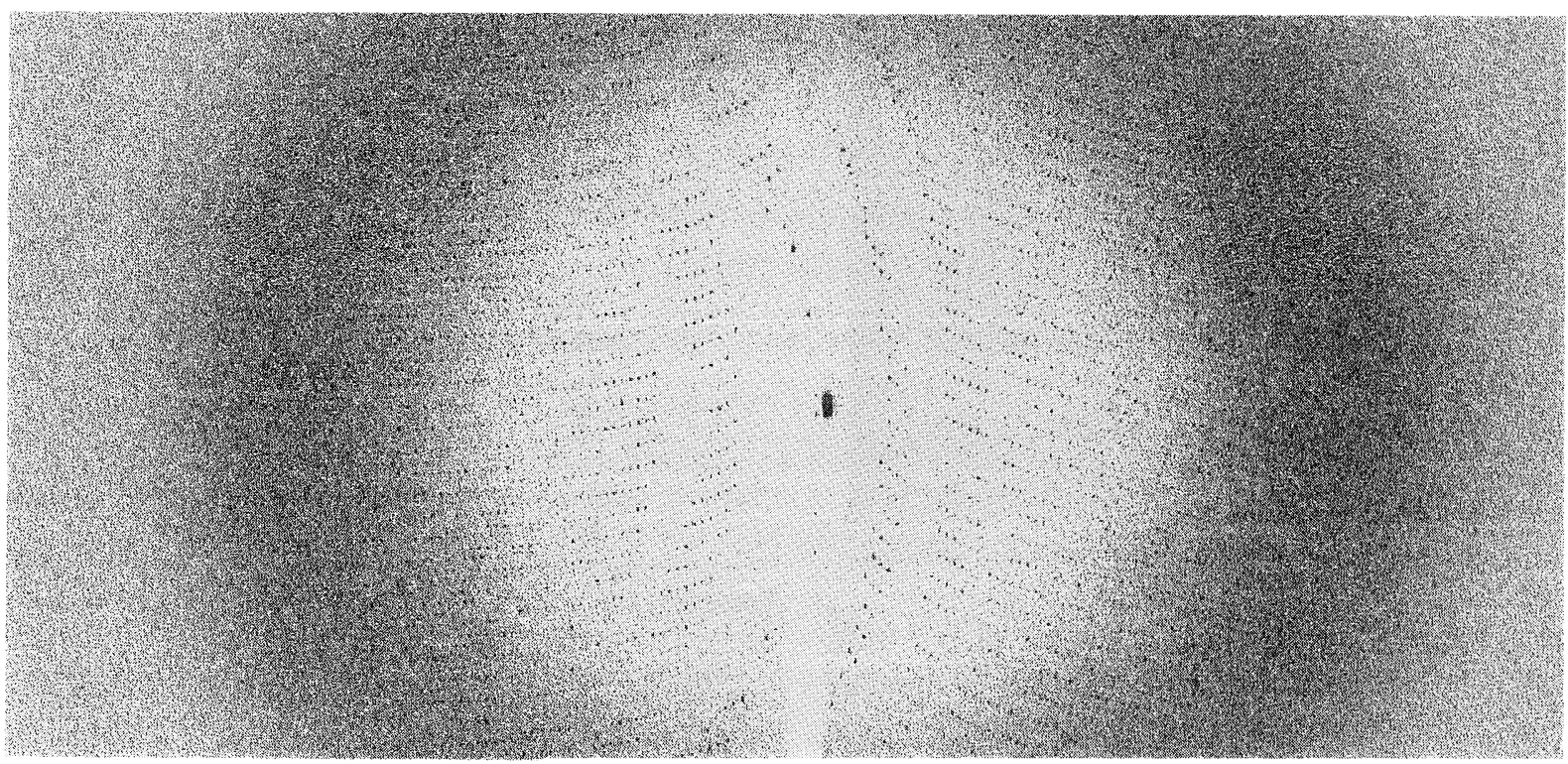

Fig. 2. An X-ray Weissenberg photograph of dimethyl sulfoxide reductase taken by the Weissenberg camera for macromolecular crystallography at the National Laboratory for High Energy Physics.

This crystal had different form from the crystal reported previously ${ }^{10)}$ which was crystallized with a reservoir solution containing $1.8 \mathrm{M}$ ammonium sulfate, $0.1 \mathrm{M}$ HEPES $\mathrm{pH} 7.5$ and 3\% 2-methyl-2,4pentanediol, and belonged to the space group $P 2_{1} 2_{1} 2_{1}$. The difference of the crystal form might be caused by the absence of 2-methyl-2,4-pentanediol. The photographs obtained with the Weissenberg camera (Fig. 2) showed that the crystals diffract X-rays at least to a resolution of $2.7 \AA$, to which $79 \%$ of the expected reflections were observed, and the merging $R$ factor $\left(R_{\text {merge }}\right)$ was 0.086 . The data statistics are shown in Table II. To determine the structure of DMSO reductase, further investigation is in progress.

Acknowledgments. We are grateful to Prof. N. Sakabe (Center for TARA, University of Tsukuba) for support of measurements at the BL6B station in the Photon Factory. This work was supported in part by a Grant-in-Aid for Scientific Research from the Ministry of Education, Science and Culture of Japan and the Sakabe project of TARA, University of Tsukuba.

\section{References}

1) Alef, K., and Kleiner, D. (1989) Biol. Fertil. Soils 8, 349-355.

2) Zinder, S.H., and Brock, T. D. (1978) Arch. Microbiol. 116, $35-40$.

3) Satoh, T., Hoshino, Y., and Kitamura, H. (1976) Arch. Microbiol. 108, 265-269.

4) Satoh, T., and Kurihara, F. N. (1987) J. Biochem. 102,
191-197.

5) Johnson, J. L., Bastian, N. R., and Rajagopalan, K. V. (1990) Proc. Natl. Acad. Sci. U.S.A. 87, 3190-3194.

6) Hilton, J. C., and Rajagopalan, K. V. (1996) Arch. Biochem. Biophys. 325, 139-143.

7) Abo, M., Tachibana, M., Okubo, A., and Yamazaki, S. (1994) Biosci. Biotech. Biochem. 58, 596-597.

8) Abo, M., Tachibana, M., Okubo, A., and Yamazaki, S. (1995) Bioorg. and Med. Chem. 3, 109-112.

9) Yamamoto, I., Wada, N., Ujiiye, T., Tachibana, M., Matsuzaki, M., Kajiwara, H., Watanabe, Y., Hirano, H., Okubo, A., Satoh, T., and Yamazaki, S. (1995) Biosci. Biotech. Biochem. 59, 1850-1855.

10) Schindelin, H., Kisker, C., Hilton, J., Rajagopalan, K. V., and Rees, D. C. (1996) Science 272, 1615-1621.

11) Yamazaki, S., Kobayashi, N., Okubo, A., Satoh, T., Tozawa, Y., Yoshimura, E., Kajiwara, H., Hirano, H., and Toda, S. (1991) Anal. Sci. 7 (Suppl.), 821-824.

12) Smith, P. K., Krohn, R. I., Hermanson, G. T., Mallia, A. K., Gartner, F. H., Provenzano, M. D., Fujimoto, E. K., Goeke, N. M., Olson, B. J., and Klenk, D. C. (1985) Anal. Biochem. 150, 76-85.

13) Jancarik, J., and Kim, S. H. (1991) J. Appl. Cryst. 24, 409-411.

14) Sakabe, N. (1983) J. Appl. Cryst. 16, 542-547.

15) Higashi, T. (1989) J. Appl. Cryst. 22, 9-18.

16) Sakabe, N. (1991) Nucl. Instr. Methods A303, 448-463.

17) Sakabe, N., Ikemizu, S., Sakabe, K., Higashi, T., Nakagawa, A., Watanabe, N., Adachi, S., and Sasaki, K. (1995) Rev. Sci. Instrum. 66, 1276-1281.

18) Bailey, S. (1994) Acta Cryst. D50, 760-763.

19) Matthews, B. W. (1968) J. Mol. Biol. 33, 491-497. 